\title{
Manuscritos do Século XVIII e Produç̃es Textuais do Século XXI: Pontos de Encontro
}

\author{
Eighteenth-Century Manuscripts and Textual Productions of \\ the Twenty-First Century: Meeting Points
}

Joyce Elaine de Almeida BARONAS * Vanessa LINI **

Resumo: A presente pesquisa objetiva constatar a presença da oralidade no texto escrito tanto na atualidade como em séculos anteriores. Para isto, num primeiro momento, serão apresentados alguns estudos já efetuados no que se refere à ortografia, posteriormente serão analisados textos atuais do ensino fundamental e, posteriormente, textos antigos, do século XVIII, a fim de confrontar e estudar diacronicamente a questão da escrita.

Palavras-chave: Escrita; Oralidade; Diacronia.

Abstract: The research aims to verify the presence of orality in the written text as much today as in centuries past. For this, at first, we introduce some studies already made with regard to spelling and we analyze date texts of elementary school and later ancient texts, the eighteenth century, to confront and examine the issue of writing diachronically

Key-words: Written; Spoken; Diachronic.

* Doutorado em Linguística e Língua Portuguesa pela Universidade Estadual Paulista Júlio de Mesquita Filho (2005). Docente da Universidade Estadual de Londrina.Contato: joyal@uel.br.

** Mestranda do Programa de Pós-Graduação em Estudos da Linguagem da Universidade Estadual de Londrina, UEL, Brasil. 


\section{Introdução}

A modalidade de escrita apresenta aspectos específicos que se diferem da modalidade oral, entretanto, a presença de marcas de oralidade no texto escrito é comum; tal questão não se restringe aos dias atuais, visto que em manuscritos do século XVIII já se pode evidenciar a influência da fala, principalmente pelo fato de, na época, não haver uma ortografia estabelecida.

Durante o processo de aquisição da língua escrita no ensino fundamental, a ocorrência de problemas ortográficos e desvios da norma padrão são evidentes, devido, principalmente, à interferência da fala na escrita. Tais ocorrências acontecem desde séculos anteriores. No início da história da Língua Portuguesa no Brasil, os usos linguísticos se deram sem tanta normatização e pode-se afirmar que a escrita era praticamente baseada na fala, visto que registros dessa época apontam variações que denunciam uma possível aproximação com a fala e uma ausência de rigidez na ortografia.

Tal constatação gerou curiosidade de comparar textos atuais de alunos do ensino fundamental com manuscritos de séculos anteriores a fim de melhor compreender os "erros escolares".

Para isso selecionaram-se 22 textos produzidos por alunos da $4^{a}$ série do ensino fundamental de uma escola pública da cidade de Cambé no Paraná e 20 textos manuscritos do século XVIII, da cidade de Paranaguá. Os textos dos alunos da $4^{\mathrm{a}}$ série foram produzidos no dia 26/11/2007, na Escola Municipal Prof. Izaura Ferreira Neves, a partir da realização de um desenho individual livre que foi o tema para a criação do texto. Já os manuscritos são documentos notariais retirados do Arquivo Público do Estado de São Paulo, fornecidos pelo projeto: Para a história do Português paranaense: estudos diacrônicos em manuscritos dos séculos XVII a XIX.

O termo "manuscrito" de origem latina "manuscriptus", que significa "escrito à mão", constitui um dos tipos de registro escrito de um texto e é de suma importância para o resgate histórico de várias áreas de estudo, principalmente no que diz respeito à escrita.

Os manuscritos que se acumulam nos acervos dos arquivos brasileiros representam uma fonte inesgotável de informações, 
permitindo a comunicação através do tempo e do espaço. Tais documentos revelam a escrita de uma época trazendo à tona a natureza do texto: seus argumentos, os propósitos, as intenções, o vocabulário e principalmente as características da escrita da época. Quanto mais se conhecem e se estudam textos manuscritos, mais revelações vêm a público.

As descobertas que esses documentos propõem despertam cada dia mais o interesse de novos pesquisadores para a realização de trabalhos acerca da história embutida nesses documentos. Um exemplo é o projeto interinstitucional: Para a História do Português Brasileiro (PHPB), coordenado pelo Prof. Dr. Ataliba Teixeira de Castilho, um projetomãe que deu origem a vários outros, em diversas instituições do Brasil. A Prof. ${ }^{a}$ Dr. ${ }^{a}$ Vanderci de Andrade Aguilera, da Universidade Estadual de Londrina, desenvolve o subprojeto: Para a História do Português Paranaense: nas veredas do Atlas Lingüistico do Paraná, cuja proposta é contribuir para a escritura de uma História da Língua Portuguesa falada no Paraná, no que se refere à formação do léxico. Esta pesquisa constitui-se dos seguintes corpora: i) Atlas Lingüístico do Paraná - ALPR - (Aguilera, 1994); ii) Boletins do Archivo Municipal de Curityba, publicados mensalmente sob iniciativa da Prefeitura de Curitiba; iii) Manuscritos do Arquivo do estado de São Paulo e de outros acervos municipais, datados dos séculos XVII, XVIII e XIX; e iv) mapas da rede hidrográfica do Paraná publicados em épocas diferentes.

Em 2005, para dar continuidade aos estudos lingüísticos paranaenses, constituiu-se um novo projeto: Para a história do Português paranaense: estudos diacrônicos em manuscritos dos séculos XVII a XIX-cuja equipe finalizou a árdua tarefa de fazer a leitura e transcrição dos 737 manuscritos do Arquivo do estado de São Paulo e de outros acervos municipais, datados dos séculos XVII, XVIII e XIX.

Este trabalho utilizou parte do corpus do projeto acima descrito, a fim de observar as características da escrita nos séculos anteriores. Realizou-se uma análise em relação aos desvios da norma padrão, com o intuito de buscar, através da história da língua, explicações para tais fatos. Observaram-se, principalmente, os desvios ortográficos e a presença de transposição dos hábitos da fala para a escrita. Com base nos dados obtidos pela pesquisa, pretende-se, pois, melhor compreender a escrita atual e a antiga, para, desta forma, colaborar 
para a melhoria do ensino de língua portuguesa no Brasil.

\section{Sobre a história ortografia da língua portuguesa}

Durante o processo de aquisição da língua escrita no ensino fundamental, a ocorrência de problemas ortográficos e desvios da norma padrão são evidentes, devido, principalmente, à interferência da fala na escrita e a falta de conhecimento da norma padrão. Tais ocorrências acontecem desde séculos anteriores. Como já citado no presente estudo, no início da história da Língua Portuguesa no Brasil, a língua se deu sem tanta normatização e pode-se afirmar que a escrita era baseada na fala, visto que registros dessa época apontam variações que denunciam uma possível aproximação com a fala e uma ausência de rigidez na ortografia. Em séculos passados a língua portuguesa ainda estava em processo de implantação como língua oficial do Brasil; portanto, as mudanças na língua no decorrer do tempo foram significativas no que se refere à ortografia.

Segundo estudos feitos por Coutinho (1967), foram três os períodos da história da ortografia portuguesa: o fonético,que começa com os primeiros documentos redigidos em português e se estende até o século XVI; o período pseudo-etimológico, que se inicia no século XVI e vai até o ano de 1904, em que aparece a Ortografia Nacional de Gonçalves Viana e o simplificado tem seu início em 1904 e continua até nossos dias. No período fonético da ortografia, a escrita procurava espelhar a pronúncia, ocorrendo grande flutuação ortográfica; nesta fase, os escritores visavam a simplificar a leitura, tornando-a próxima da língua falada, procuravam usar as letras latinas para transcrever a pronúncia do Português da época; não havia um padrão uniforme na transcrição das palavras, pois era possível encontrar um só vocábulo grafado de várias maneiras; com isto, pode-se dizer que se escrevia não para a vista, mas sim para o ouvido, já que, na época, era uma minoria que dominava a leitura. Na grafia do período pseudoetimológico procurava-se respeitar, tanto quanto possível, as letras originais da palavra, embora nenhum valor fonético representassem; são dessa época os muitos $\mathrm{CH}, \mathrm{PH}, \mathrm{TH}, \mathrm{Y}, \mathrm{K}, \mathrm{W}$, em palavras de origem grega, ou de suposta origem grega como: eschola, phrase, rhetorico, theatro, estylo, etc. Já o período simplificado foi marcado pela proposta da reforma ortográfica, em razão de os escritores da época estarem 
escrevendo cada um com uma grafia própria e diferente. O objetivo desse período era a simplificação da ortografia orientando-se pela pronúncia, sem desconsiderar a etimologia e o elemento histórico da palavra.

Desta forma, pode-se verificar que, com a evolução do tempo e conforme cada período, a grafia da Língua Portuguesa transformouse. Embora o período simplificado tenha contribuído consistentemente para certa facilitação de escrita da língua, é natural haver confusão no que diz respeito à ortografia de determinadas palavras.

\section{Dificuldades ortográficas na aquisição da escrita}

As regras de ortografia surgiram para a uniformização da escrita, já que na fala as palavras estão sujeitas a mudanças e um mesmo vocábulo pode ser pronunciado de várias maneiras, causando dificuldades na transposição da fala para a escrita. Cagliari (1999: p.50) ressalta que isso ocorre porque as relações entre letras e sons (estabelecidas na leitura) são diferentes das relações entre sons e letras (estabelecidos na escrita), devido ao fato de uma palavra poder ser pronunciada de diversas maneiras (por exemplo, póti, potchi, potch, etc.) e de ser escrita por meio de uma única forma congelada, estabelecida pela ortografia vigente (pote).

Para Cagliari (1999, p.61), escrever certas palavras segundo a ortografia vigente é uma dificuldade para muitas pessoas, mesmo que tenham uma prática de escrita relativamente intensa. Corroborando as idéias de Cagliari, Bortoni-Ricardo (2006, p. 274) ressalta que o domínio da ortografia é lento e requer muito contato com a modalidade escrita da língua. Dominar bem as regras de ortografia é um trabalho para toda a trajetória escolar e, quem sabe, para toda a vida do indivíduo.

Assim, é incorreto pensar que apenas as crianças na fase de aquisição da escrita têm dificuldades na ortografia das palavras; na realidade, qualquer ser humano, em algum momento, poderá ter dúvidas quanto à maneira correta, segundo a norma padrão, de escrever alguma palavra.

Entre as causas das dificuldades enfrentadas pelos alunos durante o processo de aquisição da escrita, observa-se uma interferência da fala na escrita e a falta de familiaridade com a norma padrão e com as 
regras da ortografia vigente. O pesquisador ainda afirma que "a variação linguística, característica inerente a toda e qualquer língua do mundo, pode constituir um grande problema para quem está adquirindo o sistema da escrita." (CAGLIARI, 1999, p.124). Isto porque o aluno pode transpor as variantes distantes da norma para o texto escrito. Em outro estudo, o autor ainda aponta que "o erro mais comum dos alunos é caracterizado por uma transcrição fonética da própria fala" (CAGLIARI, 1992, p.138).

Nesse sentido, os “erros" ortográficos são comuns e devem ser aceitos pelo professor como uma das fases de desenvolvimento da aquisição da escrita, sem preconceito e discriminação em relação à escrita do aluno.

Cagliari (1999) comenta que:

Infelizmente, muitos métodos orientam-se pelas dificuldades dos adultos, deixando de lado o ponto de vista das crianças. À medida que insistem em apavorar as crianças com fatos da escrita ortográfica, pior será a relação que esses alunos terão com a escrita futuramente.

Continuo dizendo que é muito melhor ensinar as crianças a escrever primeiro e, depois, a escrever ortograficamente... deixálas escrever o mais livremente possível, como ponto de partida e, depois fazê-las passar para a outra grafia (a ortográfica), procurando verificar se o que escreveram num primeiro momento corresponde à maneira como se deve escrever, seguindo o estabelecido pela ortografia vigente. ( 1999, p.73)

Desta forma, o aluno, em um primeiro momento, precisa familiarizar-se com a escrita, para apenas mais tarde ser corrigido ortograficamente. Cabe, então, ao professor trabalhar a norma padrão de maneira natural através da prática de escrita e de leitura, pois, quanto maior o contato com a linguagem escrita, menor serão as dúvidas em relação à ortografia das palavras.

Segundo o referido autor (1999, p.62), quem lê muito e escreve bastante, com o tempo, passa a ter cada vez menos dificuldades em escrever ortograficamente, sem precisar consultar o dicionário. Obviamente, as dificuldades aumentam quando o usuário tem pouco 
contato com a leitura, como acontece com grande parte dos alunos, principalmente devido à falta de hábito de tal atividade em seu ambiente familiar.

Portanto, os desvios da norma não devem ser vistos como uma incapacidade do aluno, mas sim como uma base para a aquisição da língua escrita.

\section{Noções de “erro"}

Diante de uma língua heterogênea e tão diversificada como a língua portuguesa, fica difícil impor uma noção de "certo e errado". Na perspectiva da gramática tradicional, ainda principal base do ensino de língua portuguesa no Brasil, "erro" é tudo aquilo que foge à norma padrão.

Com o surgimento da Sociolingüística no Brasil, na década de setenta, tornou-se necessária a revisão do conceito de "erro" no ensino de língua materna, já que essa veio revelar a heterogeneidade da língua portuguesa. Apesar disso, a mudança no ensino é lenta e o domínio da gramática normativa ainda é considerado o objetivo principal. Estudos sobre o assunto apontam que o ensino de português ideal para a atualidade exige do professor boa formação linguística e, ao mesmo tempo, domínio da gramática tradicional, para poder incluir na linguagem do aluno a norma padrão e mostrar sua necessidade social sem discriminar a variante que lhe é própria. Uma fatalidade no ensino é que essa formação não é realidade no currículo de todos os professores de língua portuguesa no Brasil.

Sobre a correção do texto do aluno, Mattos e Silva (2006), comenta que o professor não deve simplesmente "corrigir" os chamados "maus usos"; se tiver uma boa formação linguística, especificamente sociolinguística, deverá demonstrar, por exercícios, o valor social das variantes de um elemento variável no português do Brasil.

Bortoni-Ricardo (2005) também ressalta a importância da contribuição da lingüística para o ensino de línguas. Por meio de um aparato teórico e metodológico de "análise e diagnose de erros".

Verifica-se, no estudo da pesquisadora, a utilização do termo "erro", muito combatido pelos estudiosos da linguagem; entretanto, a 
autora justifica tal classificação em um trabalho publicado em 2006; segundo a estudiosa, não haveria problemas na utilização de tal termo ao se tratar de escrita, pelo fato de ser uma modalidade que não inclui o fenômeno da variação. Segundo a pesquisadora:

[...] na língua escrita o chamado "erro" representa uma transgressão de um código convencionado e prescrito pela ortografia, transgressão porque a ortografia é um código que não prevê a variação, ao contrário da língua oral que é a província da variação inerente. (BORTONI-RICARDO, 2006, p. 273).

A pesquisadora acredita na contribuição da identificação dos fenômenos lingüísticos distantes da norma padrão, para a elaboração de materiais didáticos e para a racionalização e explicação das avaliações subjetivas dos professores diante de tais fenômenos. A autora enfoca também a necessidade de o professor conhecer as características do dialeto do aluno para lidar com esses fatos lingüísticos.

Nessa perspectiva, o "erro" pode contribuir diretamente com o trabalho pedagógico do professor. Os desvios da norma podem ser ferramentas para levar o professor a conhecer as dificuldades de seus alunos, para, desta forma, redirecionar o ensino de acordo com as necessidades de cada um.

\section{Análise de dados}

Apresenta-se, a seguir, a análise de dados extraídos de textos de alunos do ensino fundamental e, posteriormente, a análise de manuscritos do século XVIII. Salienta-se que a presente análise é fundamentada no estudo de Bortoni-Ricardo (2005), em que se classificam os desvios da norma em diferentes categorias.

\subsection{Características da escrita de alunos da $4^{a}$ série do ensino fundamental}

Na presente análise, identificaram-se alguns desvios da norma padrão encontrados em produções de alunos da $4^{a}$ série do ensino fundamental que mostram as dificuldades por que passam os alunos 
no processo de aquisição da língua escrita.

No que se refere aos fatos ortográficos, constatou-se a troca de letras como um dos principais desvios da norma presente na escrita dos alunos nessa fase do ensino. Seguem alguns exemplos:

- Troca de / c / por / s / : selebrar, sedo, balansei, sentro, serto, comesei.

- Troca de / s / por / c / : cer.

- Troca de / x / por / ch /: deichamos, cochinha, relachantes.

- Troca de / ch / por / x /: bixo,xance.

- Troca de / x / por / s /: prosima.

- Troca de / ç/ por / x /: taxas.

- Troca de / ç / por / s /: comesar.

- Troca de / ç / por / ss /: carrossa.

- Troca de / s / por / z /: fizica.

- Troca de / z / por / s / : fis, disendo, diser.

- Troca de / s / por / z /: atraz.

- Troca de / ç / por / c /: justica.

- Troca de / ss / por / s / : paseio, dise, rusa, fose.

- Troca de / s / por / ss /: carinhosso, pensso.

- Troca de / ss / por / c /: nece.

- Ausência do /h/: avia, oje, ora.

- Troca de / rr / por / r /: churasco.

- Troca de / m / por / n /: assonbrada, conseguiran, ninguên, ninguen, tambén, enbora, formaran, conemos, nonte.

- Troca de / n / por / m / : imediatamemte, comdições, carme, pemsado, sabemdo, tamto, comtinuamos.

É possível que os casos de troca de / m / por / n / e / n / por $/ \mathrm{m} /$ ocorreram simplesmente pela semelhança no traçado das letras, portanto, palavras como conemos, nonte e carme que ficam com o significado e a pronúncia comprometidos com a troca, provavelmente resultam de um descuido dos redatores.

- Troca de / u / por / 1/: oltras, chegol.

- Troca de / 1 / por / u /: cauma, voutar, legau, fautava. 
Apesar de ser um desvio ortográfico, a troca de $l$ por $u$ ou vice versa, também pode ser classificado como um fato fonético. Verificase aí um caso de hipercorreção, em que provavelmente os redatores desses vocábulos já foram corrigidos ao trocar o $l$ pelo $u$ e, desta forma, acabam anulando o uso do $u$ nas demais palavras.

Tratando-se de fatos fonéticos, foram encontrados na escrita dos alunos casos de monotongação de ditongos decrescentes e de queda do / r / final nas formas verbais, casos que ocorrem em função da transposição da fala para escrita, mas que não são considerados estigmatizados. Os casos encontrados são:

- Monotongação de ditongos decrescentes: hove, janero, mangedora, pexaria, quemadinho.

- Queda do / r / final nas formas verbais: viaja, havendo a supressão do $\mathrm{r}$ do infinitivo .

Por fim, como casos resultantes da interferência da fala na escrita que causa estigmatização e uma avaliação negativa, destacou-se o seguinte caso:

- Monotongação do ditongo nasal em "muito": munta.

Além dessas ocorrências, foram encontrados outros desvios da norma que serão abordados a seguir:

- Diferentes formas do diminutivo: arvrinha, luisinhas.

- Marcas da Oralidade: xampãs / xampã, shoppin, repreta, fizero, plei, pesina.

- Ditongação: pessouas, voceis, voua.

- Desmembramento do vocábulo: em bora, em triga, da qui, a moleser, des de, a quela, na quele. Nesses casos, os redatores entenderam os itens "de", "da", “em", “na”, como uma preposição, assim como o "a” um artigo, e os utilizaram separadamente.

- Troca de T por D: pergunda. 
Sobre essa ocorrência, Mattoso Câmara (1972), esclarece ser um caso de confusão entre consoante surda $(\mathrm{t})$ intervocálica com sonora $(d)$.

\subsection{Estudo comparativo entre a escrita de alunos do ensino fundamental e a escrita de documentos manuscritos do século XVII}

Como já referido anteriormente, foi possível constatar que alguns desvios da norma encontrados em produções de alunos do ensino fundamental coincidem com a escrita encontrada em documentos de séculos passados.

Os manuscritos que foram selecionados para a pesquisa em questão podem ser situados no período pseudo-etimológico devido às datas de seus registros (século XVIII), apesar de a escrita apresentar ainda características do período fonético da ortografia. Williams (1973, p.41) afirma ter sido o século XVIII o "período de amargas polêmicas ortográficas; e terminou por predomínio arrasador da ortografia etimológica".

Classificam-se a seguir os desvios da norma encontrados nos documentos. Entre as características do período pseudo-etimólogico, destaca-se a escrita irregular, com grande flutuação na ortografia das palavras, sendo possível encontrar, no mesmo texto ou escrito por um mesmo punho, a mesma palavra grafada de formas diferentes. São exemplos ocorridos nos manuscritos:

$$
\begin{aligned}
& \text { tambem / tanbem - (mesmo escriba); } \\
& \text { Homildes / Omildes - (mesmo escriba); } \\
& \text { leaes / Leais - ( mesmo escriba e mesmo documento). }
\end{aligned}
$$

Esse tipo de ocorrência também se repete nos textos atuais. Nos textos dos alunos que compõem o corpus desse trabalho, uma mesma palavra também aparece escrita de formas diferentes no mesmo texto:

$$
\text { celebrar / selebrar (mesmo aluno e mesmo texto); }
$$


presents / presentes (mesmo aluno e mesmo texto);

torbina / turbina (mesmo aluno e mesmo texto);

muito / muitu (mesmo aluno e mesmo texto);

centro / sentro (mesmo aluno e mesmo texto).

A confusão entre letras e fonemas é comum nos documentos, assim como nas produções escritas dos alunos. Tanto no caso dos manuscritos quanto nos textos atuais, isto explica-se pela falta de conhecimento e domínio da norma padrão. No primeiro caso, não existia ainda uma norma padrão definida, já no segundo, a interferência da linguagem não-padrão adquirida fora da escola e a estranheza em relação à nova forma da linguagem escrita, podem ser os fatores responsáveis pelos desvios da norma.

Os fatos ortográficos comuns entre a escrita atual e a escrita do século XVII retirados dos manuscritos são:

- Troca de / c / por / s /: notisias, exersendo / exêrSendo, sinco, serteza.

- Troca de / s / por / c /: concelho.

- Troca de / m / por / n /: tanbem, deZenbro.

- Troca de / n / por / m /: emtram, emviar / emviassemos, emtregar / emtrega, emsino, numCa .

- Troca de / ss / por / c /: socego, pagace.

- Troca de / c / por / ss /: meresser.

- Troca de / ss / por / ç /: foçe, andaçem.

- Troca de / ss / por / s /: assim, pasa, paSar, expresei, nosos.

- Troca de / ç/ por / c /: Serviço.

- Troca de / r / por / rr /: honrra.

- Troca de / x / por / s /: pRosimo.

- Troca de / s / por / z /: pRezentes.

- Troca de / z / por / s /: des.

Em relação à fonética, a escrita do século XVIII apresenta apenas os casos de neutralização das vogais / o / e / u / e / e / / i /, os demais desvios encontrados na escrita dos alunos não aparecem nos 
documentos.

- Neutralização das vogais / e / e / i /: emformado, meLitares, emposiuel, partecipantes.

- Neutralização das vogais / o / e / u /: inpusibilidade, comprimento, custuma.

Outras ocorrências presentes nos manuscritos analisados são:

- Marcas da Oralidade: coase.

- Desmembramento do vocábulo: sete centos.

- Acentuação: tambem, prosimo, Pernagua, athe, remedio, proprias.

Diante da comparação entre a escrita antiga e a atual, pode-se afirmar que, embora presentes de maneira mais expressiva nos textos atuais, várias formas linguísticas diferenciadas já eram comuns em séculos anteriores. Tal constatação é importante para a formação do professor de língua portuguesa, que deve dar uma atenção especial aos desvios da norma apresentados pelos alunos, levando-os a perceber as formas inadequadas e a compreender de forma mais clara os motivos das confusões na escrita dos textos.

\section{Considerações finais}

Com base nos dados apresentados, constata-se que, embora, a modalidade de escrita apresenta aspectos bastante peculiares, diferenciando-se, portanto, da modalidade oral, é fato comum a interferência da oralidade no texto escrito, não só atualmente, mas também em séculos anteriores. Tal constatação é de suma importância para o ensino de Língua Portuguesa, pois, a partir de uma visão diacrônica do processo de escrita, o professor estará mais apto para lidar com os desvios da norma presentes nos textos de seus alunos, sabendo não só identificar tais desvios, mas também lidar com eles. Além disso, ressalta-se a necessidade de elaboração de materiais didáticos adequados para abordar a escrita e a oralidade. 


\section{Referências}

AGUILERA, Vanderci de Andrade. Atlas lingüístico do Paraná. Curitiba: Imprensa Oficial, 1994.

BORTONI-RICARDO, Stella Maris. Nós cheguemu na escola e agora?: sociolingüística e educação. São Paulo: Parábola, 2005.

. O estatuto do erro na língua oral e escrita. In: GORSKI, Edair Maria, COELHO, Izete Lehmkuhl (orgs.) Sociolingüistica e ensino: contribuições para a formação do professor de língua. Florianópolis: EdUFSC, 2006.

CAGLIARI, Luiz Carlos. Alfabetização e linguística.. 5.ed. São Paulo: Scipione, 1992.

. Diante das Letras: a escrita na alfabetização. São Paulo: Fapesp, 1999.

CÂMARA JR., J. Mattoso. Dispersos de J. Mattoso Câmara Jr. Seleção e introdução por Carlos Eduardo Falcão Uchôa. Rio de Janeiro : Fundação Getúlio Vargas, 1972.

CASTILHO, Ataliba Teixeira de. Variação dialetal e ensino institucionalizado da língua portuguesa. In: BAGNO, Marcos (org.). Lingüistica da norma. São Paulo: Loyola, 2002.

COUTINHO, Ismael de Lima. Pontos de Gramática Histórica. 5.ed. Rio de Janeiro: Livraria Acadêmica, 1967.

MATTOS e SILVA, Rosa Virgínia. Dizem que vai mal o vernáculo no Brasil. In: O português são dois: novas fronteiras, velhos problemas. São Paulo: Parábola, 2004, p. 11-36.

. "O português são dois"...ainda "em busca do tempo perdido". In: GORSKI, Edair Maria; COELHO, Izete Lehmkuhl (orgs.). Sociolingüística e ensino: contribuições para a formação do professor de língua. 
Florianópolis: UFSC, 2006.

NARO, Anthony e SCHERRE, Maria Marta Pereira. Origens do português brasileiro. São Paulo: Parábola, 2007.

SPINA, Segismundo. História da língua portuguesa III: segunda metade do século XVI e século XVII. São Paulo: Ática, 1987.

VIANA, Aniceto dos Reis Gonçalves: Ortografia Nacional. Simplificação e uniformização sistematica das ortografias portuguesas. Lisboa, Viúva Tavares Cardoso/ Porto, Tip. da Empresa Lit. e Tip., 1904 - xvi-454 p. 